\title{
Improving Building Fabric Energy Efficiency in Hot-Humid Climates using Dynamic Insulation
}

\begin{abstract}
New effective technologies and materials that have the potential to reduce energy demand with excellent energy efficiency and low environmental impact are urgently required in the Gulf region. Dynamic insulation, which functions by recycling fabric heat loss back to the building, has been established theoretically and proven in pilot projects. It sets the green, low carbon benchmark for thermal insulation in buildings.

This paper presents details of the Eco-Villa, its construction, how the performance of the villa was monitored, and the findings from the initial monitoring phase and the Dynamic Simulation Model (DSM). The villa was tested in two modes, bypass (static) and dynamic. The static $U$ value of the external envelop wall was estimated at $0.24 \mathrm{~W} / \mathrm{m}^{2} \mathrm{~K}$ in bypass mode. The theoretical dynamic $U$ value changed from 0.24 to $0.05 \mathrm{~W} / \mathrm{m}^{2} \mathrm{~K}$ when the ventilation air flow was varied from 0 to llitres $/ \mathrm{s} / \mathrm{m}^{2}$, with a further small reduction occurring when the flow rate increased beyond llitres $/ \mathrm{s} / \mathrm{m}^{2}$. The design ventilation rate for the Eco-Villa was 0.8 litres $/ \mathrm{s} / \mathrm{m}^{2}$, which yielded a theoretical dynamic $U$ value of $0.063 \mathrm{~W} / \mathrm{m}^{2} \mathrm{~K}$ compared to a measured $U$ value of $0.125 \mathrm{~W} / \mathrm{m}^{2} \mathrm{~K}$. The reduction in the fabric conduction gain was found to be $41 \%$ whereas the estimate from the DSM was $38 \%$.

The results demonstrate the fabric energy efficiency improvements that can be achieved through the use of dynamic insulation. They show that the average air conditioning peak load demand was reduced in dynamic mode by $25 \%$ and that the villa consumed $5.0 \%$ less electrical energy for air conditioning. The results from the DSM suggest the annual cooling energy consumption would be reduced by $3.8 \%$.
\end{abstract}

\section{NOMENCLATURE}

$A z \quad$ Zone floor area $\left(\mathrm{m}^{2}\right)$

C Specific Heat Capacity $(\mathrm{J} / \mathrm{kg} \mathrm{K})$

$h \quad$ Overall wall height $(\mathrm{m})$

$P \quad$ Power $(\mathrm{W})$

$Q \quad$ Heat flux $\left(\mathrm{W} / \mathrm{m}^{2}\right)$

$R \quad$ Resistance $\left(\mathrm{m}^{2} \mathrm{~K} / \mathrm{W}\right)$

$T \quad$ Temperature $(\mathrm{K})$

$U \quad$ Overall heat transfer coefficient $\left(\mathrm{W} / \mathrm{m}^{2} \mathrm{~K}\right)$

$v \quad$ Velocity $(\mathrm{m} / \mathrm{s})$

$\mathrm{Va} \quad$ Outdoor airflow rate required per unit area $\left(\mathrm{m}^{3} \mathrm{~s}^{-1} / \mathrm{m}^{2}\right)$

$\mathrm{Vbz} \quad$ Breathing zone outdoor airflow rate $\left(\mathrm{m}^{3} \mathrm{~s}^{-1}\right)$

$V p \quad$ Outdoor airflow rate required per person $\left(\mathrm{m}^{3} \mathrm{~s}^{-1} /\right.$ person)

$x \quad$ Width $(\mathrm{m})$

$y \quad$ Height $(\mathrm{m})$

Zp Zone Population

Greek

$\rho_{a} \quad$ Density $\left(\mathrm{kg} / \mathrm{m}^{3}\right)$ 


$\begin{array}{ll}\text { Subscripts } & \\ \text { a } & \text { Air } \\ \text { c } & \text { Cavity } \\ \text { d } & \text { Dynamic } \\ \text { i } & \text { Indoor } \\ \text { o } & \text { Outdoor } \\ \text { s } & \text { Static } \\ \text { y } & \text { Elevation }\end{array}$

\section{INTRODUCTION}

Rising standards in the face of increasing pollution levels mean that higher volumes of clean, fresh air are needed in order to improve indoor air quality (IAQ). This gives the Heating, Ventilation and Air Conditioning (HVAC) engineer a higher thermal load to remove from the building and raises maintenance issues. This is especially true in very hot, humid climates such as in the Gulf Region, where outdoor air has to be conditioned to the desired comfort humidity and temperature before it can be supplied to indoor spaces. Air conditioning at high ventilation rate requires additional equipment and energy to be used. The cooling process also very often requires some post-heating of the tempered air before it is supplied to indoor spaces.

The current rate of energy consumption for air conditioning and the high capital investment that is required are not sustainable. Neither is a building design methodology that relies on reduction of fresh ventilation air to reduce cooling energy at the expense of compromised IAQ. In essence, introduction of fresh ventilation air into buildings affects both energy consumption and indoor air quality. When space conditioning is necessary, the energy required to maintain comfortable conditions and acceptable IAQ increases with the rate of ventilation.

A building that uses an air permeable, insulated external envelope can significantly reduce energy use for both cooling and heating while at the same time allowing higher than normal volumes of clean, optionally filtered ventilation air to be introduced to the building at all times, Elsarrag and Imbabi (2009) and Elsarrag et al. (2006).

This approach is at odds with systematic reductions in infiltration and ventilation rates to reduce energy consumption that in recent years have led to the development of the air tight, hermetically sealed building. It is however very much in line with the higher ventilation rate dictated both by better comfort requirements and by the most recent standards such as ASHRAE (62-2007), where there is acknowledgement of ventilation rates in modern buildings to deliver to occupants the benefits of healthy indoors environments.

The aim of this paper is to report the energy efficiency that was achieved through use of dynamic insulation in the Eco-Villa pilot project.The dual focus of the paper is thus fabric energy efficiency and HVAC energy use reduction attributed to dynamic insulation. The paper summarises the monitoring results over a period of 8 weeks, between January 2010 and March 2010. 


\section{OVERVIEW OF DYNAMIC INSULATION}

Research on dynamic insulation goes back to 1978, attributed to a prototype experimental building completed in France, Anon (1984). This was followed by a second prototype - with improved design and more extensive instrumentation - built in 1981 and commissioned in late 1982, Claridge (1991). Several definitions of dynamic insulation can be found in the literature; simply stated it is a means of reducing building heat loss without the use of massive thermal insulation. It is achieved by recycling the heat conducted through the fabric or reducing the temperature gradient across the wall section by means of a suitable heat transport fluid - usually air.

Using a proportion of the building envelope as the ventilation source means that the flow velocity through the intervening media required to deliver the number of fresh air changes per hour is very low. As a result, it has been shown that both efficient conduction heat recovery and filtration of the incoming air can take place as a function of air change rate, Taylor and Imbabi (2000) - i.e., the more ventilation air is drawn in the higher the heat recovery.

A formal classification of generic dynamic insulation system has been reported in the literature by Arquis and Langlais (1986) and the three types which can be associated with building applications which are permeodynamic, parietodynamic and thermodynamic insulation. They reported a theoretical model and an efficiency parameter for evaluation of dynamic insulation systems as compared to conventional insulation. In the case of permeodynamic insulation, they describe air flow in a direction opposite to the conduction heat flow through a permeable porous medium, generally mineral fibre which acts as a heat exchanger -i.e., the air flow changes the local temperature within the porous medium. The slope of the temperature profile at the cold side is lower and consequently heat losses are reduced. For parietodynamic insulation, the fresh air supplied to the building circulates through an air gap along the wall which is preheated before it enters the building. The principle of thermodynamic insulation is similar to permeodynamic, counter-flow configuration, but the air circulates in a closed circuit independent of the ventilation system. A heat exchanger is required to recover what is gained by the air as it flows through the porous medium.

Bailly (1986) presented a comprehensive and informative review of dynamic insulation in general, where such systems were compared to the operation of an air-to-air heat exchanger. Transient models and experiments were used to evaluate the performance of dynamic insulation systems during the heating season and energy savings of the order of 7 to $14 \%$ were reported.

Models for heat and mass transfer in dynamic insulation were established in the mid-90s (Taylor et al, 1996; Taylor and Imbabi, 1997, 2000). Elsarrag et al. (2006) reported the results from the first field trial of the dynamic insulation in Abu Dhabi. Elsarrag and Imbabi (2009) investigated the use of dynamic insulation in a building facade for zone local insulation and ventilation. The savings in energy and $\mathrm{CO}_{2}$ reduction were quantified against existing standards in the Gulf Region. They showed that dynamic insulation can provide tempered fresh air, raise energy efficiency and reduce air conditioning energy demand without compromising IAQ or thermal comfort level.

Figure 1 schematically illustrates the differences between dynamic versus static insulation wall constructions. 


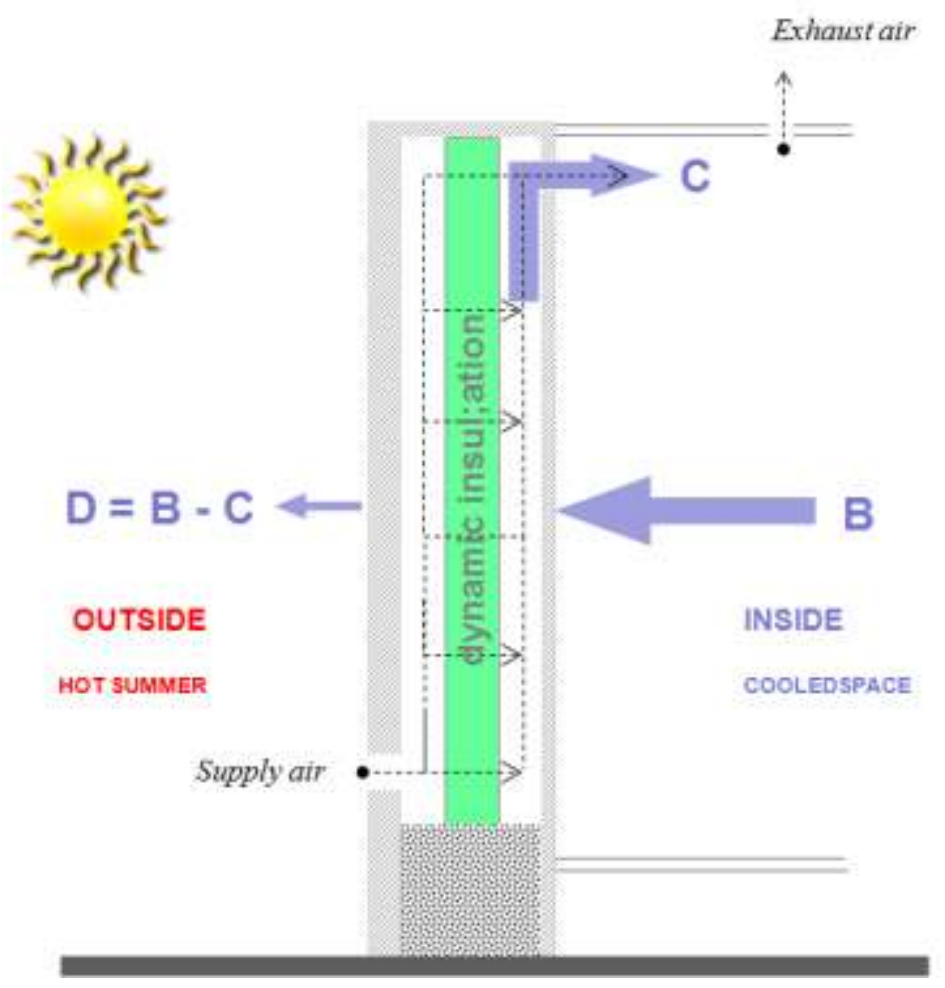

(a) Dynamic wall

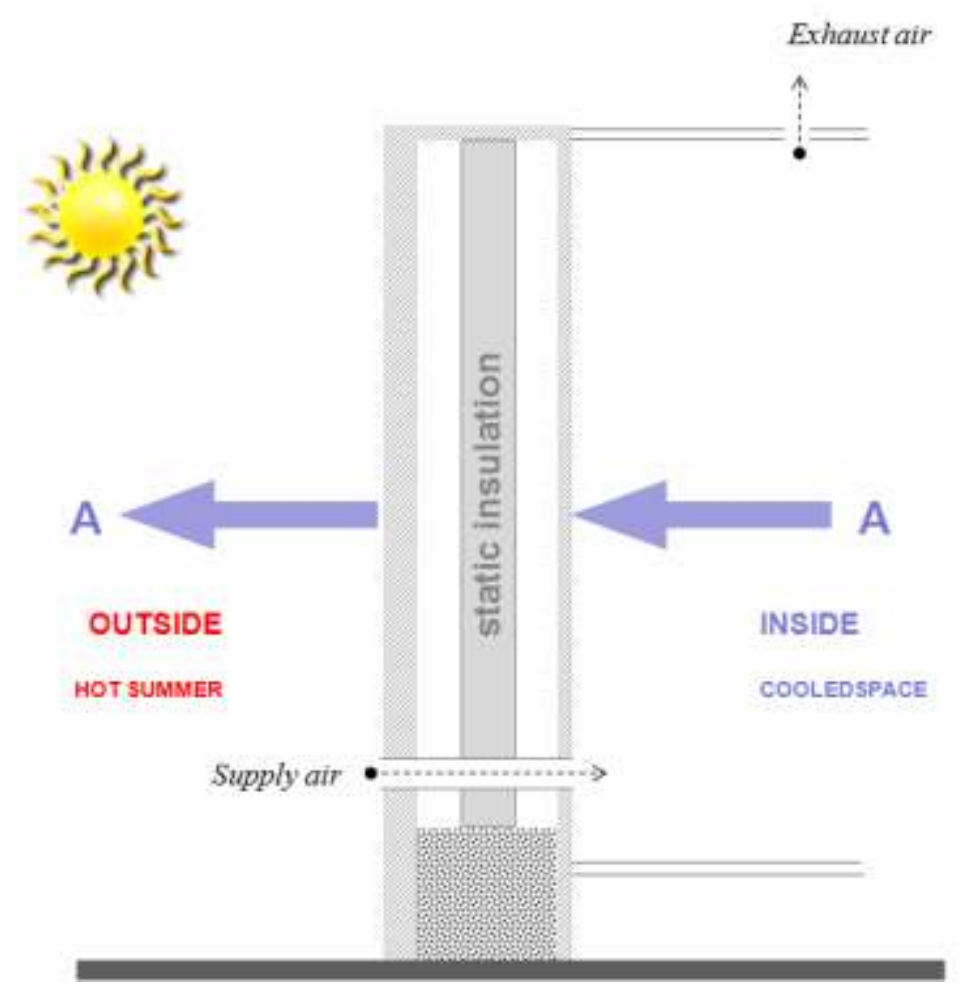

(b) Static wall (bypass)

Figure 1. Wall construction schematics 


\section{DESCRIPTION OF THE ECO-VILLA}

The Eco-Villa was constructed in United Arab Emirates (UAE) to evaluate the use of dynamic insulation in the hot climate of the Gulf Region. The villa, a detached family home on two floors, was built using pre-cast concrete panels.

The external wall construction details are shown in Figure 2. Assemblies of air permeable dynamic insulation cells were fitted internally over the available wall area and sealed in place using an independent, self-supporting gypsum board lining system that contained and protected the cell as shown in Figure 3.
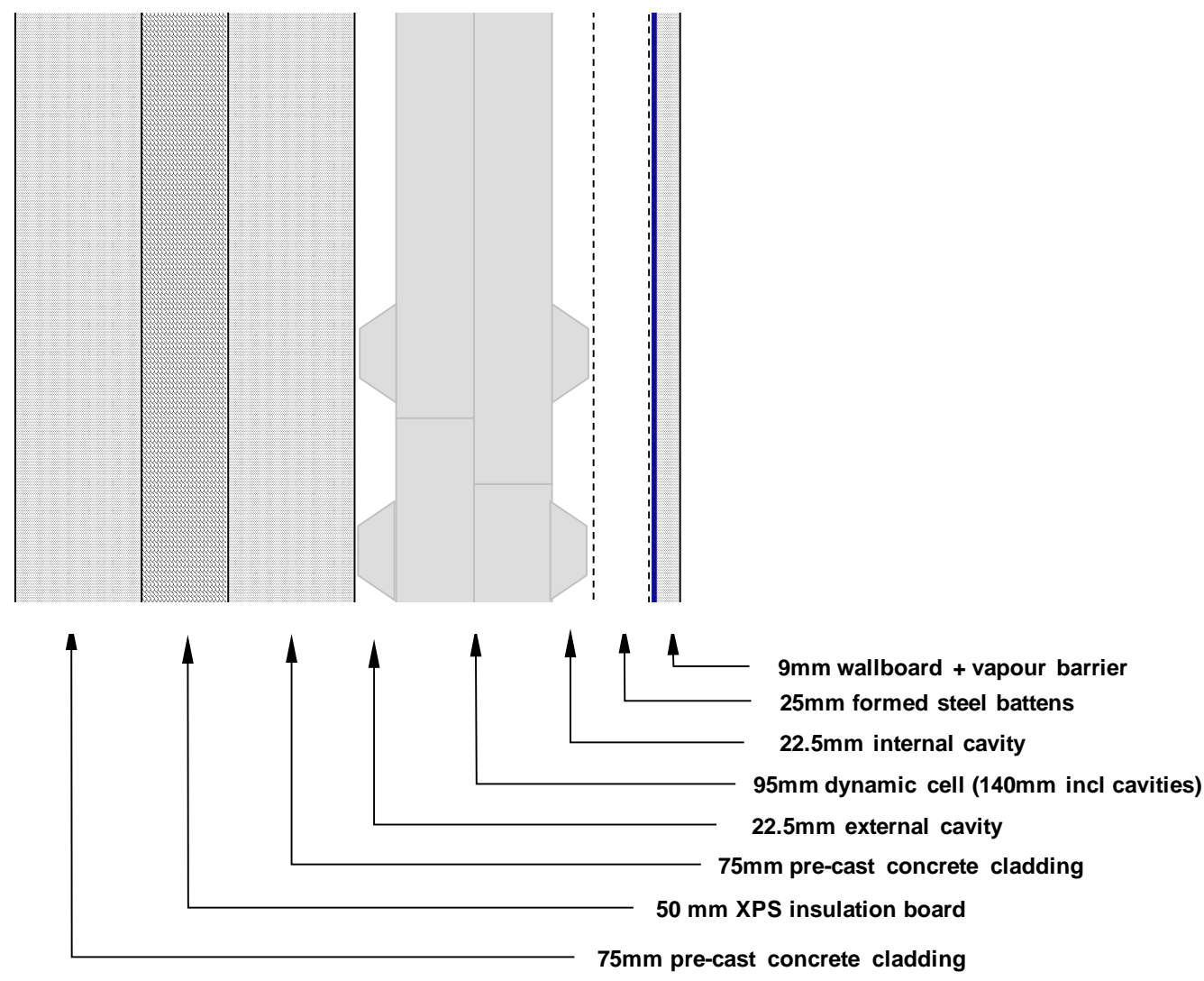

Figure 2. Wall construction layers of the Eco-Villa 


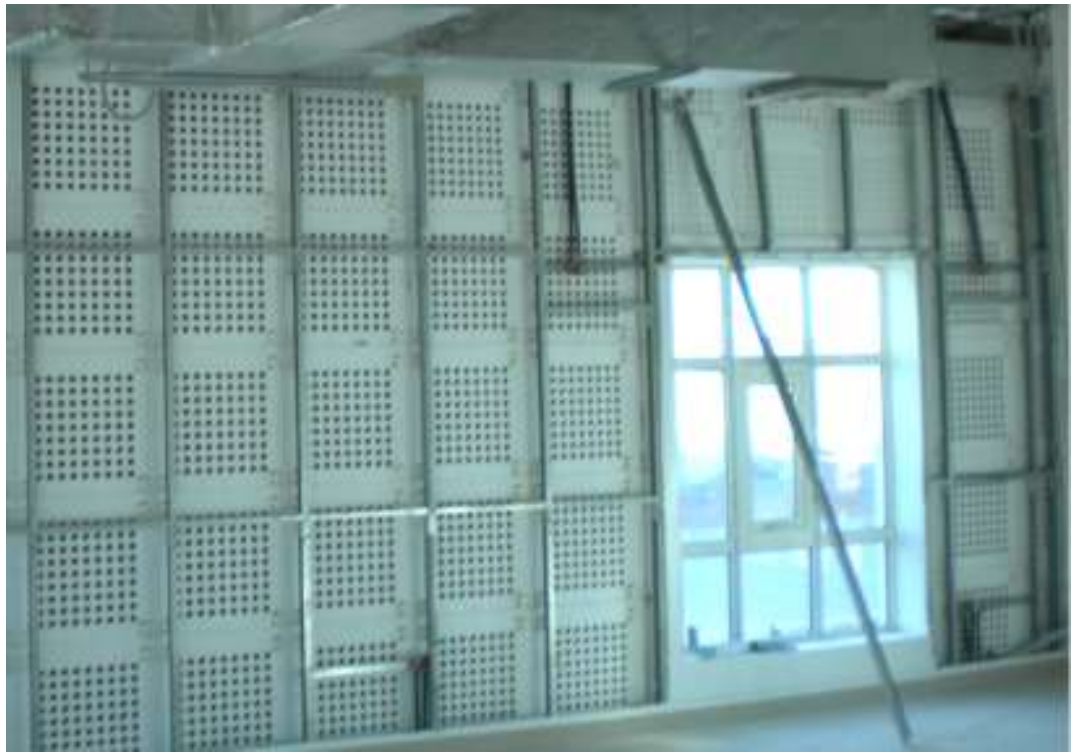

(a) Prior to cladding

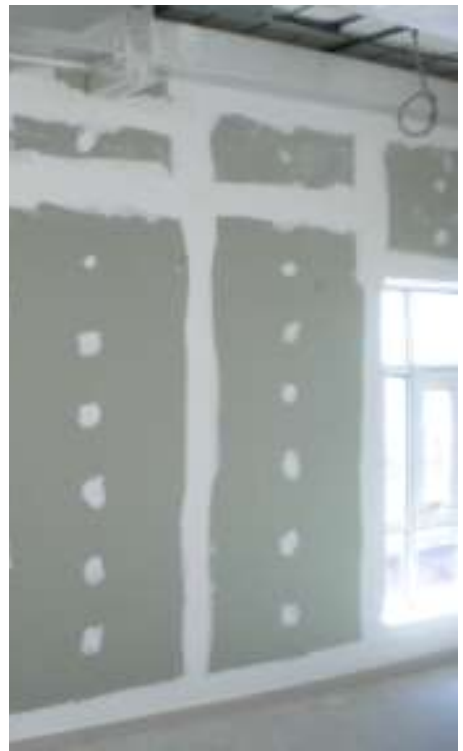

(b) After cladding

Figure 3. Dynamic insulation applied to external walls.

In operation, ventilation air flows through the rainscreen cladding via an inlet vent into an air cavity, then through the dynamic insulation cells into an internal air cavity, and thereafter through the dry wall cladding via an outlet vent or duct. The roof and floor were insulated by conventional static insulation but internal partitions were left without insulation.

The arrangement that was deployed in the Eco-Villa was such that the external walls of each floor operated independently - i.e., without the incoming fresh air having to pass through more than one floor height of dynamic insulation. Inlet ventilation louvers were fitted with integral sand traps to wall faces and a ring-duct in the ceiling void was used to collect the incoming air and deliver it to the roof-mounted central air conditioning system.

In order to enable comparative performance to be benchmarked, a bypass duct was installed at roof level to provide fresh ventilation air when the villa is operated in bypass-mode - i.e., with no air flow through the insulated walls The design outdoor airflow required in the breathing zone of the occupied space was determined according to ASHRAE standard (622007).

The HVAC schematics in Figure 4, superimposed on the roof and ground floor plans, show the basic layout of equipment, ducts and sensors (for both temperature and humidity) that were installed in the villa ( $\mathrm{W}$ is the wall sensor location, $\mathrm{R}$ the room and $\mathrm{D}$ the air duct). The measurements were taken with the villa unoccupied, i.e., lighting and domestic hot water remained switched off during operation. In addition to measurement points shown in Figure 4 , an energy meter was installed.

Direct A/B comparisons of $U$ value and energy consumption in dynamic versus bypass modes of operation of the villa over a period of 2 month was carried out using a ventilation rate of $0.0008 \mathrm{~m}^{3} / \mathrm{s}(0.8$ litres $/ \mathrm{s})$ per $\mathrm{m}^{2}$ of the external wall area. 


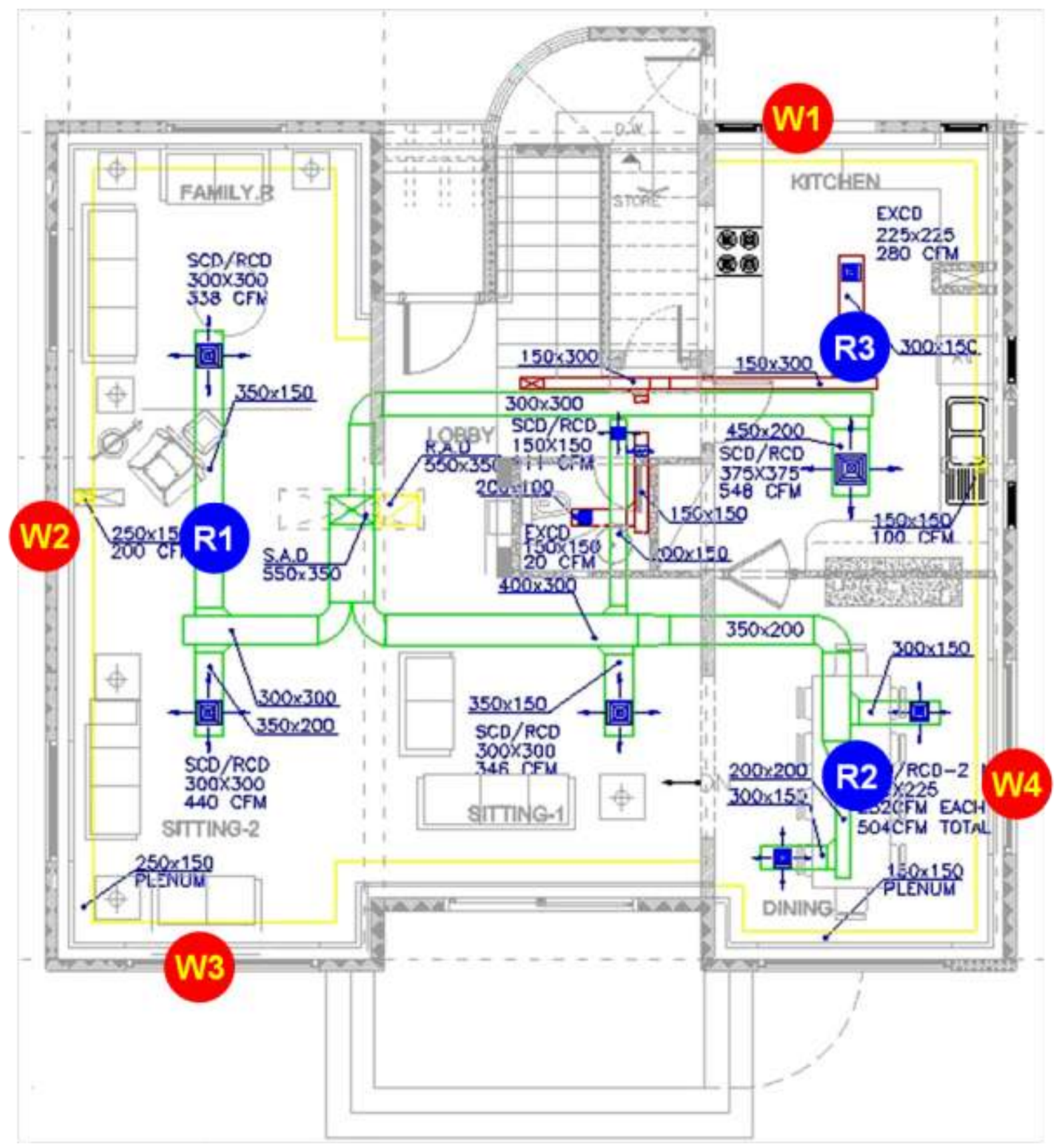

(a) Ground floor 


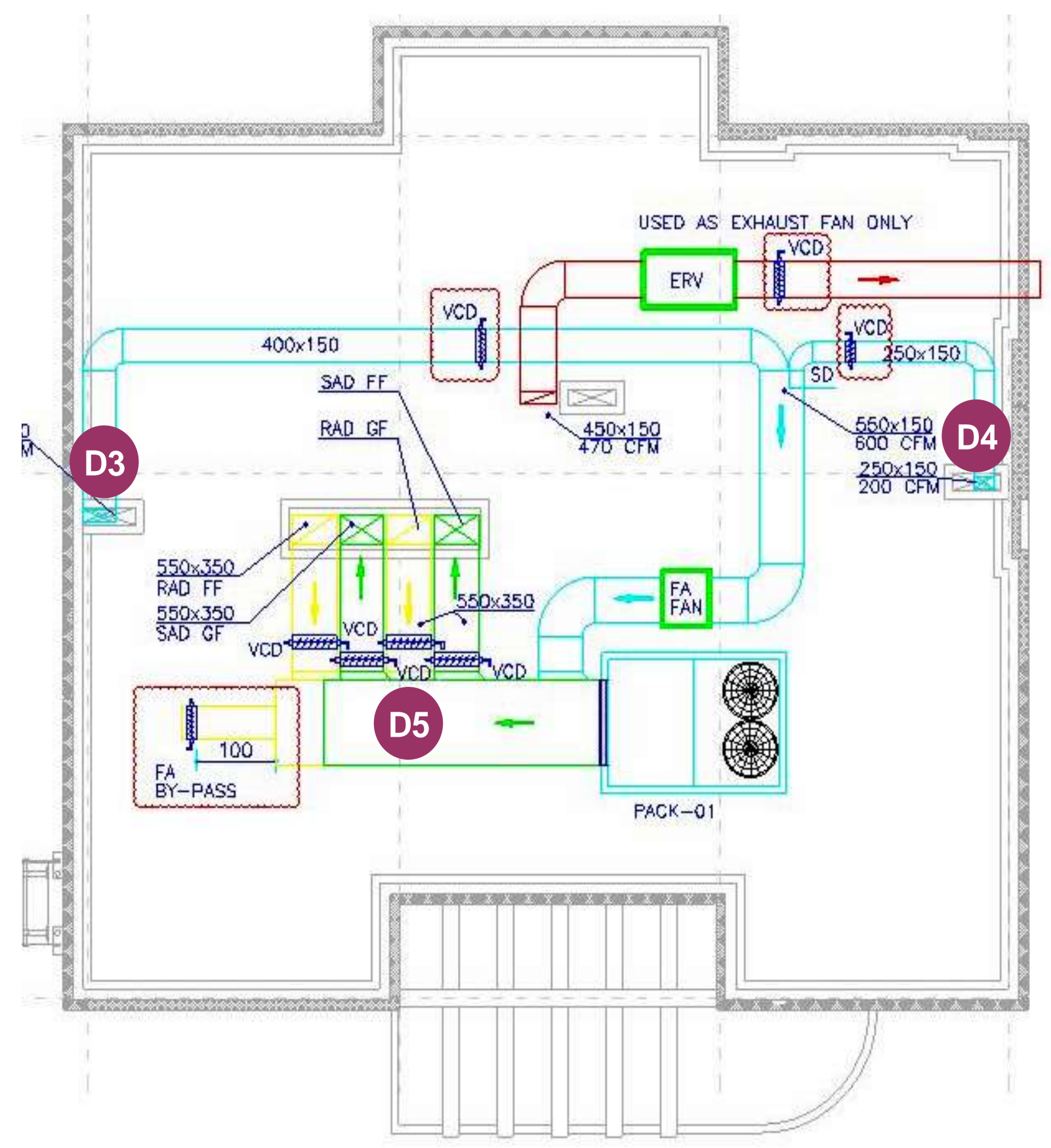

(b) Roof

Figure 4. HVAC and sensor layout

\section{THEORETICAL DYNAMIC U VALUE}

A theoretical 1-D model of a wall of unit width and height $h$, comprising an outer rain screen, external cavity, permeodynamic insulation layer, internal cavity and dry wall lining, as shown in Figure 5, has been developed. The model combines permeodynamic heat recovery as air flows through the insulation layer and parietodynamic heat recovery as the same air flows across the internal cavity to the outlet from the wall. This model, its derivation and the resulting governing equations will now be summarised. 


\section{Internal and External Cavities Temperatures:}

For external cavity, see Figure 5, the temperature is governed by the fabric conductance and ventilation conductance playing no part.

$$
\begin{aligned}
& \frac{T_{y 1}-T_{o}}{T_{i}-T_{o}}=\frac{R_{o}}{R_{o}+R_{d}+R_{i}} \\
& T_{y 1}=T_{o}+\frac{R_{o}\left(T_{i}-T_{o}\right)}{R_{o}+R_{d}+R_{i}}
\end{aligned}
$$

Where $R_{d}$ is given in Taylor et al. (1996) as:

$$
R_{d}=\frac{\exp \left(\rho_{a} C_{a} v_{a} R_{s}\right)-1}{\rho_{a} C_{a} v_{a}}
$$

$\rho_{a}$ and $C_{a}$ are the density and specific heat capacity of air, and $R_{s}$ the thermal resistance of dynamic insulation when $v_{a}=0$.

For internal cavity, see Figure 6, temperature is governed by both fabric conductance and ventilation conductance.

$$
\begin{aligned}
& \Delta P_{i}=\left[\frac{T_{y 2}-T_{i}}{R_{i}}\right] \Delta y \\
& \Delta P_{o}=\left[\frac{T_{o}-T_{y 2}}{R_{o}+R_{d}}\right] \Delta y \\
& \Delta P_{\text {vent }}=\rho_{a} C_{a} v_{a}\left(T_{o}-T_{y 1}\right) \Delta y
\end{aligned}
$$

Conservation of energy yields the following equation:

$$
\Delta T_{y 2}=\frac{\Delta P_{o}-\Delta P_{i}+\rho_{a} C_{a} v_{a}\left(T_{o}-T_{y 1}\right) \Delta y}{\rho_{a} C_{a} x_{c 2} v_{y 2}}
$$

Substituting equations (4) and (5) in (7):

$$
\frac{\Delta T_{y 2}}{\Delta y}=\frac{A-T_{y 2}}{C y}
$$

Where

$$
\begin{aligned}
& A=\left[\frac{T_{i}\left(R_{o}+R_{d}\right)+T_{o} R_{i}+\rho_{a} C_{a} v_{a} R_{i}\left(R_{o}+R_{d}\right)\left(T_{o}-T_{y 1}\right)}{R_{o}+R_{d}+R_{i}}\right] \\
& C=\left[\frac{\rho_{a} C_{a} v_{a} R_{i}\left(R_{o}+R_{d}\right)}{R_{o}+R_{d}+R_{i}}\right]
\end{aligned}
$$


At the limit, as $\square y \rightarrow 0$,

$$
\frac{d T_{y 2}}{d y}=\frac{A-T_{y 2}}{C y}
$$

Using the Integrating Factor Method, the solution of Eq (9) yields:

$$
T_{y 2}(y)=A+\frac{F^{*}}{e^{\frac{C y^{2}}{2}}}
$$

Where $F^{*}$ is an integration constant ( $A$ and $C$ are as previously defined).

The value of this constant can be determined from consideration of the boundary conditions at the inlet - i.e., at $\mathrm{y}=0$ :

$$
\begin{aligned}
& \rho_{a} C_{a} v_{a}\left(T_{o}-T_{y 2}(0)\right)=\frac{T_{y 2}(0)-T_{i}}{R_{i}}+\frac{T_{y 2}(0)-T_{i}}{R_{o}+R_{d}} \\
& T_{y 2}(0)=\frac{T_{o}\left(\rho_{a} C_{a} v_{a} R_{i}\left(R_{o}+R_{d}\right)\right)+T_{i}\left(R_{i}+R_{o}+R_{d}\right)}{R_{o}+R_{d}+R_{i}+\rho_{a} C_{a} v_{a} R_{i}\left(R_{o}+R_{d}\right)}
\end{aligned}
$$

Substituting the above expression in Eq (10):

$$
F^{*}=T_{y 2}(0)-A=\frac{T_{o}\left(\rho_{a} C_{a} v_{a} R_{i}\left(R_{o}+R_{d}\right)\right)+T_{i}\left(R_{o}+R_{d}+R_{i}\right)}{R_{o}+R_{d}+R_{i}+\rho_{a} C_{a} v_{a} R_{i}\left(R_{o}+R_{d}\right)}-A
$$

Thus:

$T_{y 2}(y)=A+\frac{\left[\frac{T_{o}\left(\rho_{a} C_{a} v_{a} R_{i}\left(R_{o}+R_{d}\right)\right)+T_{i}\left(R_{o}+R_{d}+R_{i}\right)}{R_{o}+R_{d}+R_{i}+\rho_{a} C_{a} v_{a} R_{i}\left(R_{o}+R_{d}\right)}-A\right]}{e^{\frac{C y^{2}}{2}}}$

\section{$\underline{\text { Heat Flux Equations }}$}

The power loss per unit area, $\mathrm{Q}_{\mathrm{id}}$, see Figure 6, is given from:

$$
\frac{\Delta P_{o}}{\Delta y}=\frac{T_{o}-T_{y 1}}{R_{o}}=\frac{d P_{o}}{d y} \quad \text { as } \Delta y \rightarrow 0
$$

Integration of Eq (15) over the full wall height $\mathrm{h}$ yields:

$$
P_{o}=\frac{h\left(T_{o}-T_{y 1}\right)}{R_{o}}=h Q_{1 d} \Rightarrow Q_{1 d}=\frac{\left(T_{o}-T_{y 1}\right)}{R_{o}}
$$


The power gain per unit area, $\mathrm{Q}_{2 \mathrm{~d}}$, see Figure 6, is given from:

$$
\frac{\Delta P_{i}}{\Delta y}=\frac{T_{y 2}-T_{i}}{R_{i}}=\frac{d P_{i}}{d y} \quad \text { as } \Delta y \rightarrow 0
$$

Integration of Eq (17) over the full wall height h yields:

$$
\begin{aligned}
& P_{i}=\frac{h}{R_{i}} \int_{0}^{h}\left(T_{y 2}-T_{i}\right) d y=h Q_{2 d} \\
& Q_{2 d}=-\frac{1}{h R_{i}} \int_{0}^{h}\left(\left(T_{i}-A\right)-\frac{F^{*}}{e^{\frac{C y^{2}}{2}}}\right) d y=\left(\frac{A-T_{i}}{R_{i}}\right)-\frac{F^{*} \sqrt{\frac{\pi}{2}}}{h R_{i} \sqrt{C}} \operatorname{erf}\left(\frac{h \sqrt{C}}{\sqrt{2}}\right)
\end{aligned}
$$

Where $\operatorname{erf}(z)$ is the error function.

\section{Dynamic U Values:}

The dynamic heat loss coefficient from the wall, $\mathrm{U}_{1 \mathrm{~d}}$, is thus:

$$
U_{1 d}=\frac{Q_{1 d}}{T_{o}-T_{i}}=\frac{\left(T_{o}-T_{y 1}\right)}{R_{o}\left(T_{o}-T_{i}\right)}
$$

This defines what the author and others (Dalehaug (1993) and Dimoudi et al. (2004)) have called the dynamic U-value of the wall construction - i.e., the net thermal transmission loss to ambient.

The corresponding dynamic heat gain coefficient by the wall, $\mathrm{U}_{2 \mathrm{~d}}$, is:

$$
U_{2 d}=\frac{Q_{2 d}}{T_{o}-T_{i}}=\frac{1}{R_{i}}\left(\left(\frac{A-T_{i}}{T_{o}-T_{i}}\right)-\frac{F^{*} \sqrt{\frac{\pi}{2}}}{h \sqrt{C}\left(T_{o}-T_{i}\right)} \operatorname{erf}\left(\frac{h \sqrt{C}}{\sqrt{2}}\right)\right)
$$

The dynamic heat gain coefficient by the wall, $U_{2 d}$, is the perceived thermal transmission rate per unit area of dry wall. 


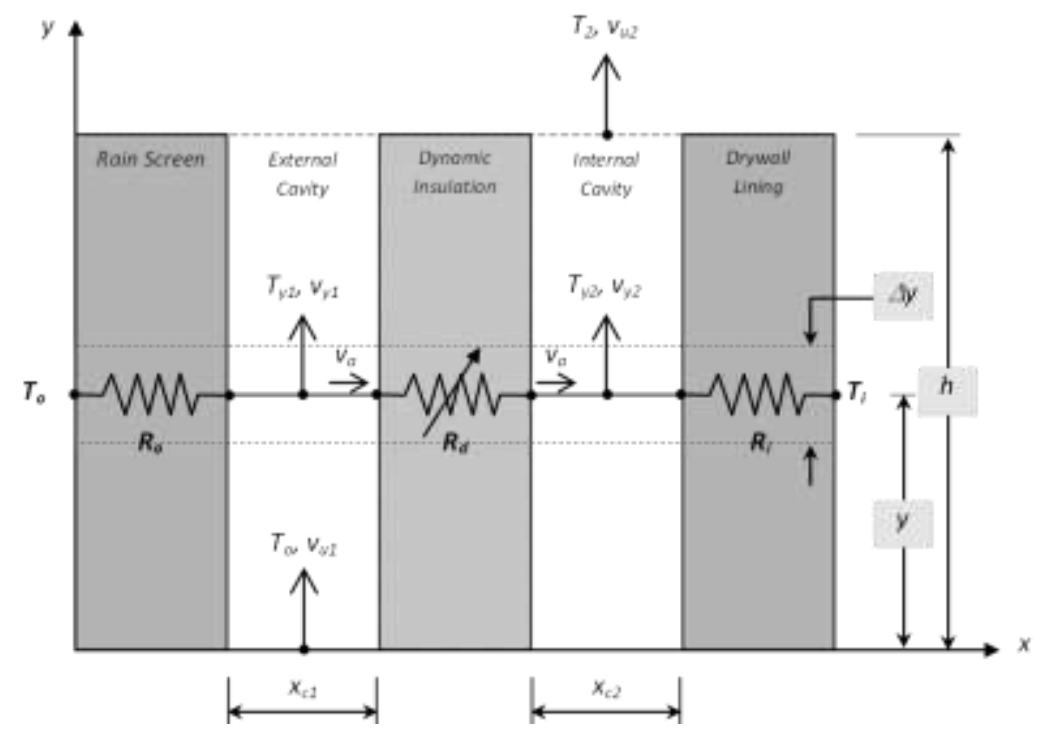

Figure 5. Model geometry and notation

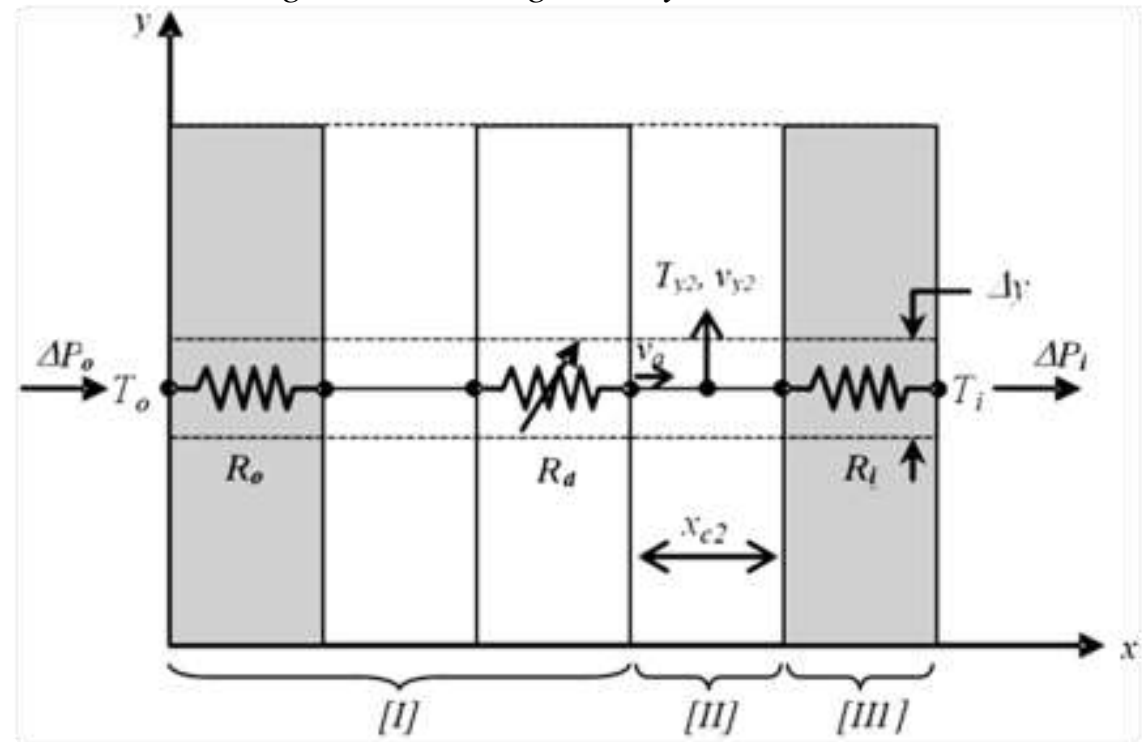

Figure 6. Energy balance schematics

\section{RESULTS AND DISCUSSION}

\section{External Wall U values}

To obtain the theoretical external wall $U$ value for the Eco-Villa, the physical properties of the external wall construction shown in Figure 2 were used in the above equations using air flow rate ranges of 0 to 4 litres/s per $\mathrm{m}^{2}$ of external wall area. The dynamic and dry wall $\mathrm{U}$ values calculated from equations (20) and (21) are plotted in Figures 7 and 8 respectively.

It can be seen that at zero flow rate, the bypass mode, the external wall $U$ value is $0.24 \mathrm{~W} / \mathrm{m}^{2} \mathrm{~K}$ which represents the static $\mathrm{U}$ value of the wall. The dynamic $\mathrm{U}$ value reduces from 0.24 to $0.05 \mathrm{~W} / \mathrm{m}^{2} \mathrm{~K}$ when the ventilation air flow is varied from 0 to 1 litres $/ \mathrm{s} / \mathrm{m}^{2}$ and only slight reduction occurs when the flow rate increases from 1 to 4 litres $/ \mathrm{s} / \mathrm{m}^{2}$, see Figure 7 . 
In contrast, the $\mathrm{U}$ value at the dry wall face increases from 0.24 to $3.6 \mathrm{~W} / \mathrm{m}^{2} \mathrm{~K}$, see Figure 8 . The tested villa design ventilation rate is 0.8 litres $/ \mathrm{s} / \mathrm{m}^{2}$ which provides a design theoretical dynamic $U$ value of $0.063 \mathrm{~W} / \mathrm{m}^{2} \mathrm{~K}$. The perceived theoretical dry wall $U$ value is $1 \mathrm{~W} / \mathrm{m}^{2} \mathrm{~K}$. The increase in the static $U$ value at the dry wall side to $1 \mathrm{~W} / \mathrm{m}^{2} \mathrm{~K}$ at 0.81 itres $/ \mathrm{s} / \mathrm{m}^{2}$ represents direct cooling of air in the dry wall cavity space, after it has passed the dynamic insulation.

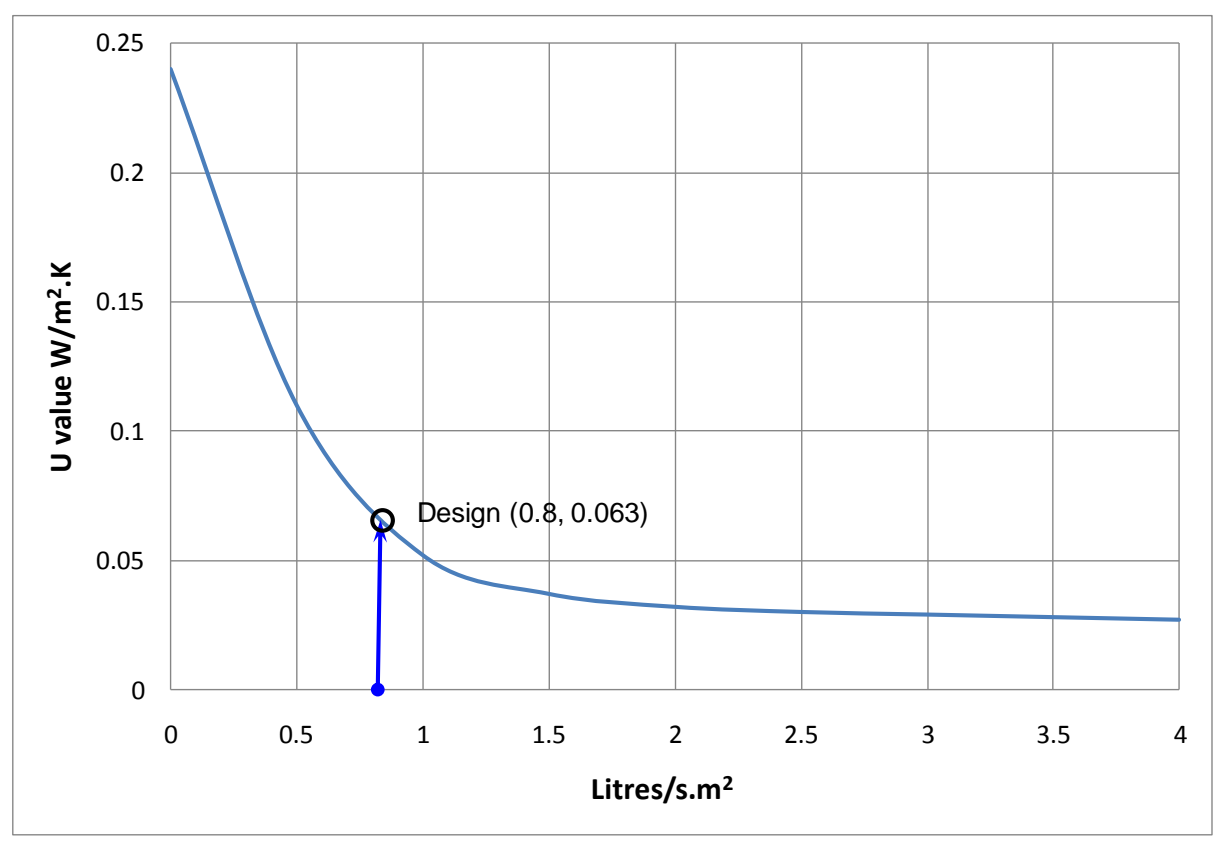

Figure 7. Theoretical dynamic $U$ value $\left(U_{1 d}\right)$

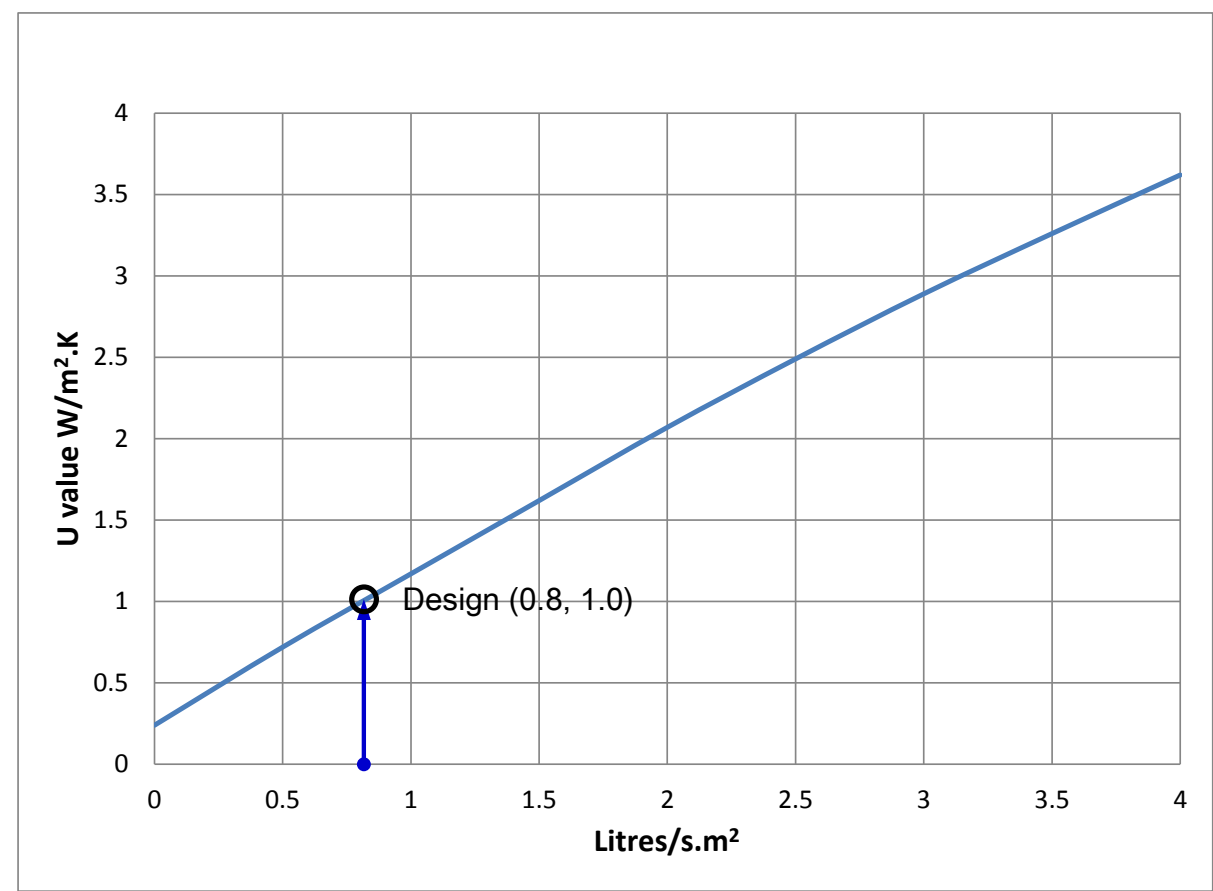

Figure 8. Dry wall perceived dynamic $U$ value $\left(U_{2 d}\right)$ 
To verify the actual operating $U$ value for the Eco-Villa for both dynamic mode and static mode the wall conduction load was determined. The energy consumed by the villa, measured using the energy meter, in the absence of internal gains (the villa was not occupied), is only of the air conditioning load and includes fabric, solar and ventilation loads. The data from dynamic versus static modes of operation was obtained from sequential runs of 1 week's duration in each case. The results that are presented in this paper were taken from two consecutive weeks that have comparable indoor and outdoor conditions. Figures 9 and 10 show the measured indoor and outdoor air temperatures for the two modes over these two consecutive weeks. The indoor set point was kept constant at $23^{\circ} \mathrm{C}$ for both static and dynamic cases.

A Dynamic Simulation Model (DSM) for the Eco-Villa was developed using Integrated Environmental Solutions software (IES v6.3) for both the static mode and dynamic mode to obtain the external wall conduction gain. The DSM was used to allow the theoretical breakdown of annual energy demand for both static and dynamic modes to be estimated.

Figure 11 shows a $38 \%$ reduction in the conduction heat transfer within the measure period using DSM where the actual data has shown $41 \%$ reduction within the tested period. There is thus reasonable agreement in the percentage reduction between the DSM and measured values.

Figure 12 tracks a like-for-like observed dynamic $U$ value reduction of $48 \%$ against the static baseline reference calculated from the theoretical model at 0.81 litres $/ \mathrm{s} / \mathrm{m}^{2}$, corresponding to a static U-value of $0.125 \mathrm{~W} / \mathrm{m}^{2} \mathrm{~K}$. The theoretical model shows this to be equivalent to a $74 \%$ reduction from the static case compared to the design theoretical value of $0.063 \mathrm{~W} / \mathrm{m}^{2} \mathrm{~K}$ at 0.8 litres $/ \mathrm{s} / \mathrm{m}^{2}$.

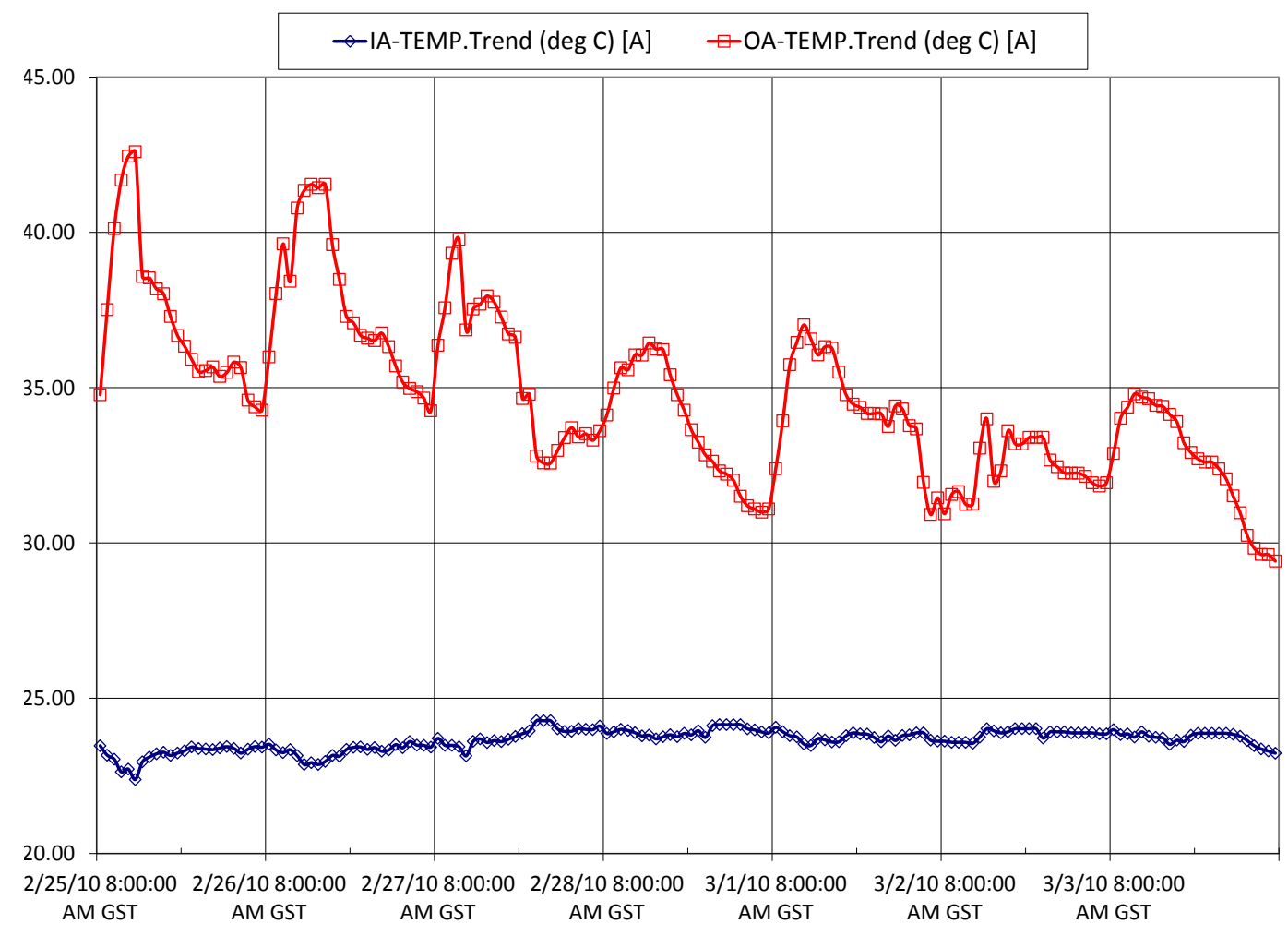

Figure 9. Measured outdoor and indoor temperatures for the bypass baseline case 


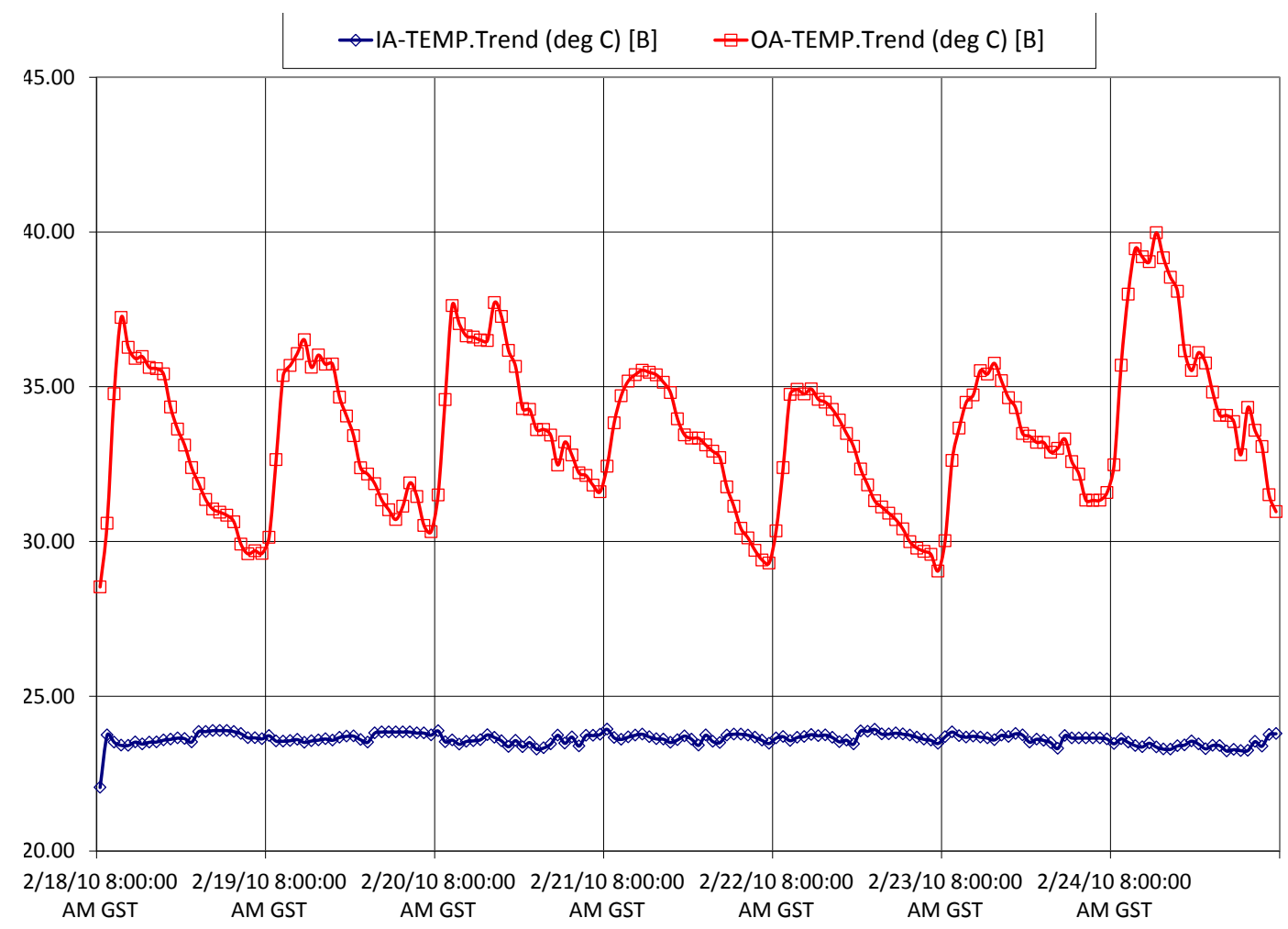

Figure 10. Measured outdoor and indoor temperatures for the dynamic case

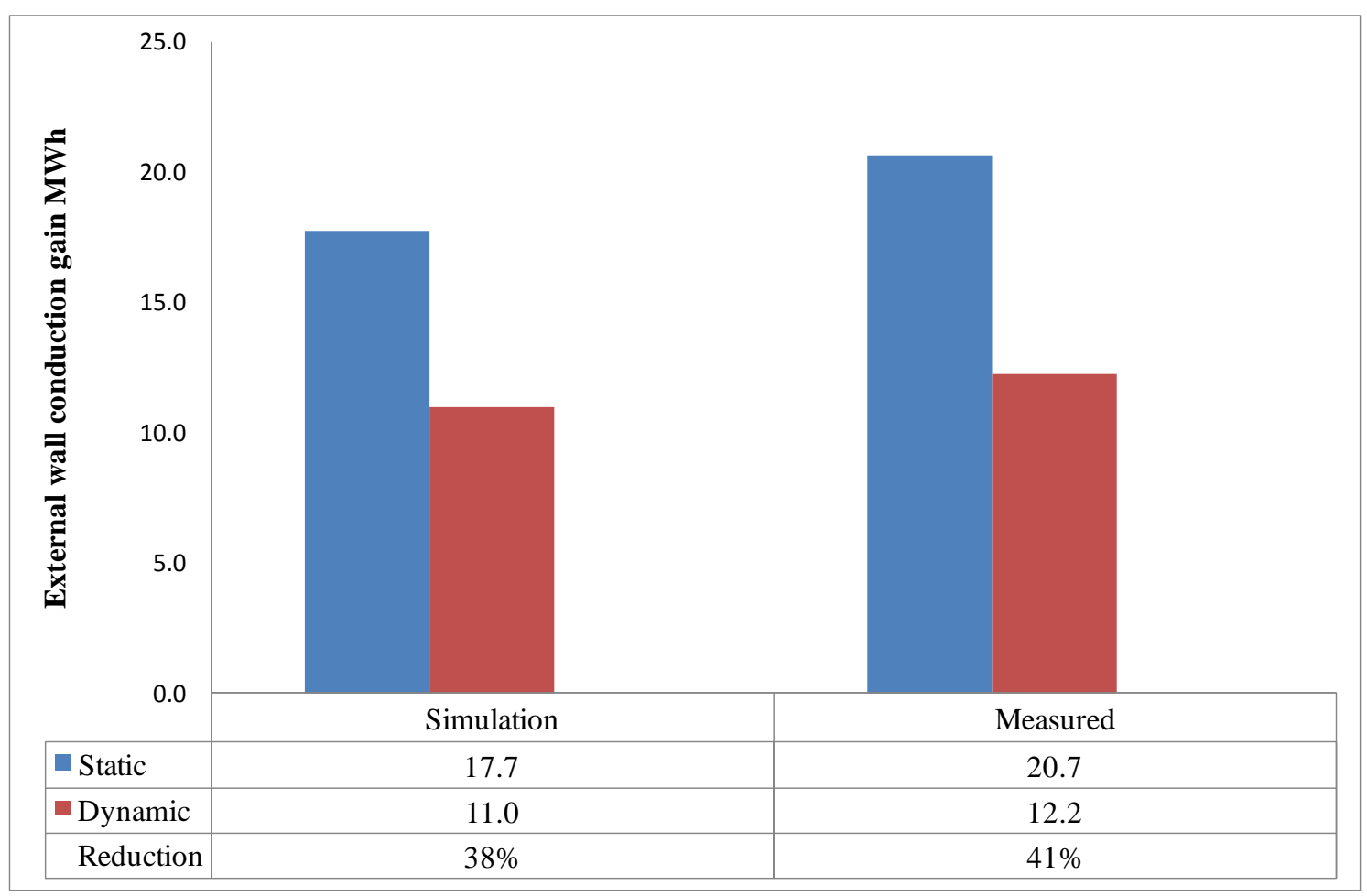

Figure 11. External wall conduction gain 


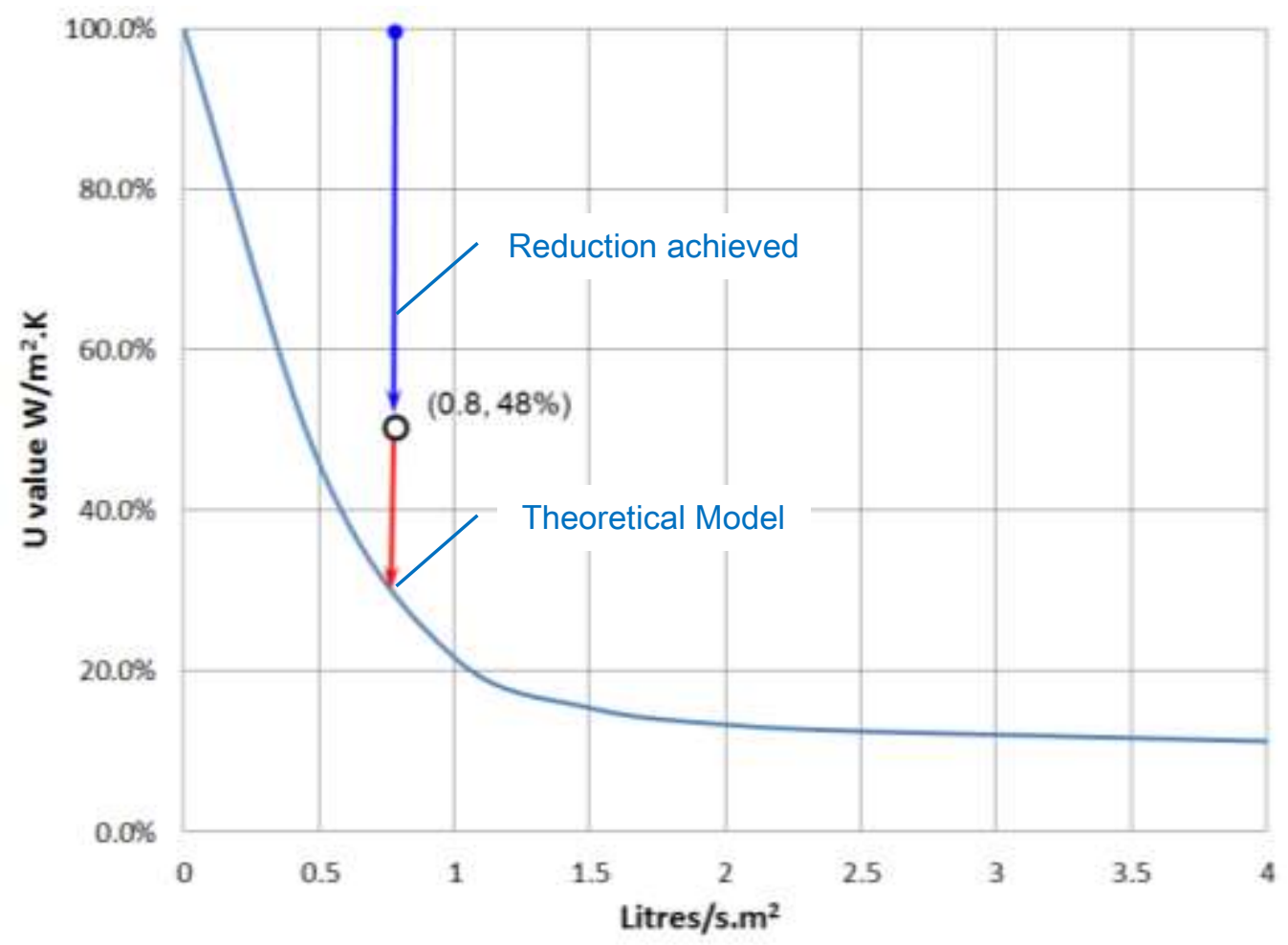

Figure 12. Measured versus theoretical dynamic $U$ values

This is an excellent result that also shows there is room for improvement. The theoretical model, for example, does not include allowance for the effects of solar gain or latent heat effects, both of which can be significant in a hot humid climate. As a consequence, the rate of heat loss will be higher than otherwise predicted.

Another factor is air flow uniformity across the active wall area. Dynamic insulation is tolerant of small variations in air flow, with gains in heat recovery efficiency in high flow areas compensating for reductions in areas of low flow, but large variations will ultimately degrade performance. This is a system-level issue and an engineering solution is required.

The DSM predicts an annual reduction of $44 \%$ in external wall gain in dynamic mode compared to the bypass mode as shown in Figure 13, which is promising.

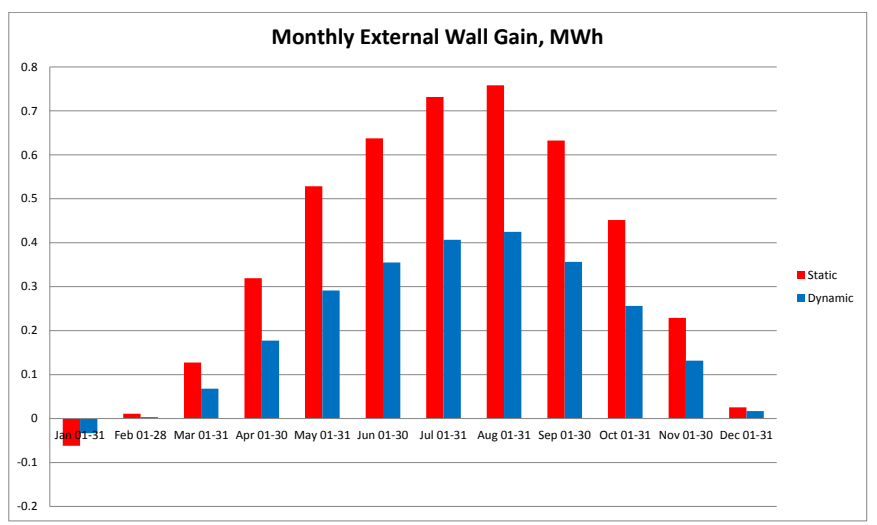

(a)

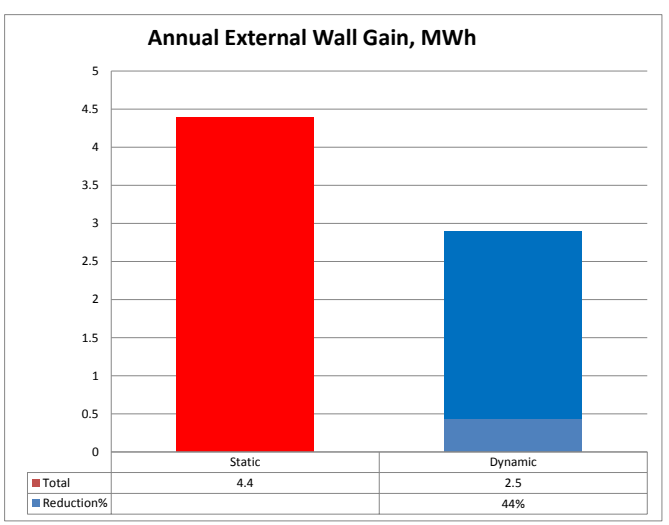

(b)

Figure 13. External Wall Conduction Gain a) Monthly; b) Annual 


\section{Energy Consumption}

In order to enable direct $\mathrm{A} / \mathrm{B}$ comparisons to be made between the measured values in dynamic and bypass modes, the measured air conditioning load values have been weather corrected.The energy consumption in both cases was thus normalised against the temperature difference between the indoor and outdoor environments. The weather corrected $\mathrm{A} / \mathrm{C}$ energy demand is plotted for the baseline and dynamic cases in Figures 14 and 15. The results show that the average air conditioning peak load demand is reduced in the dynamic mode by $25 \%$. In dynamic mode the villa used 5.0\% less electrical energy for air conditioning $\mathrm{kWh} / \mathrm{K}$ - see Figure16. Figure 17 compares the predicted monthly and annual energy consumptions from the DSM. As shown, the annual cooling energy consumption is reduced by $3.8 \%$.

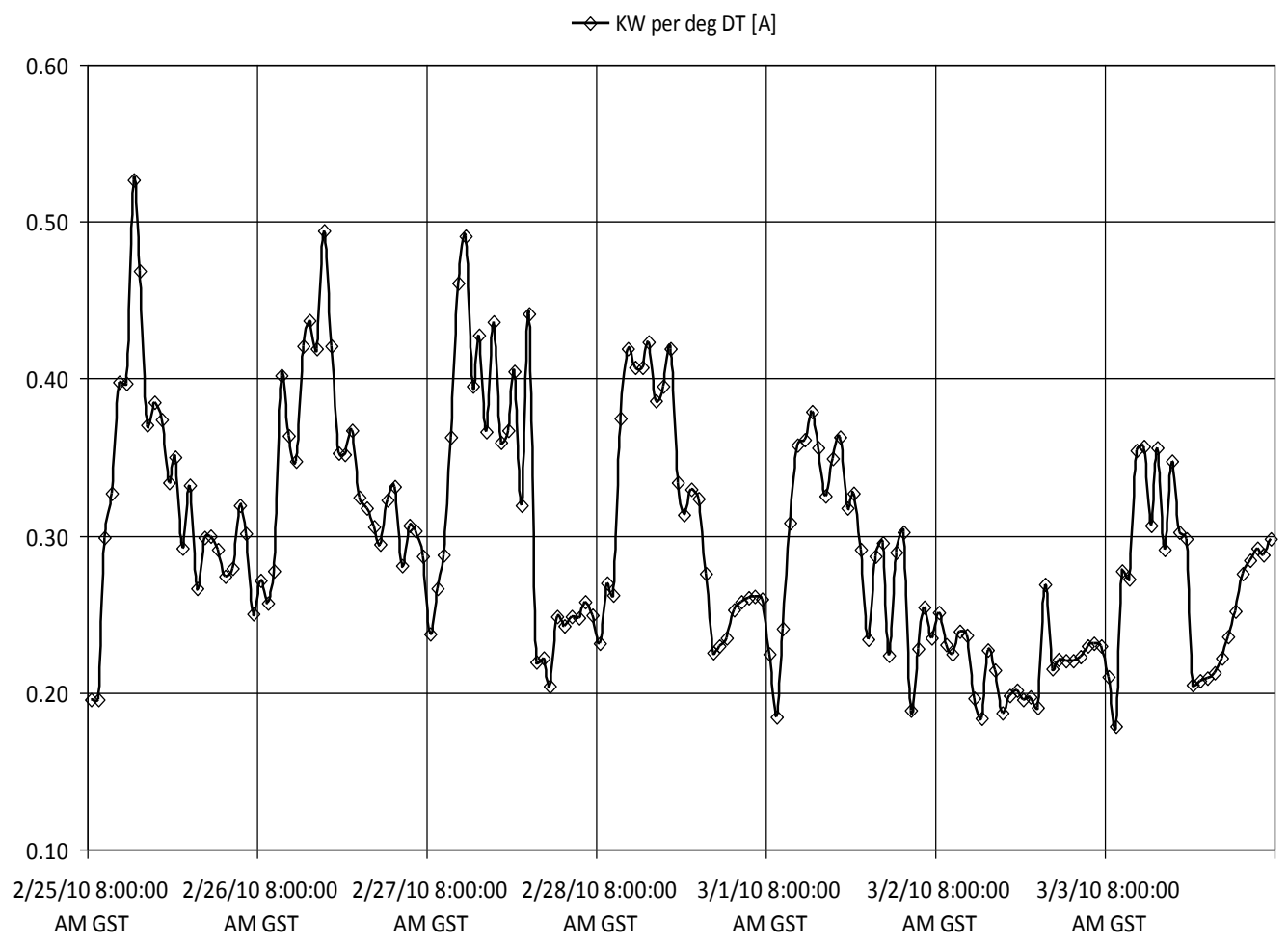

Figure 14. The weather corrected A/C energy demand for the bypass baseline case 


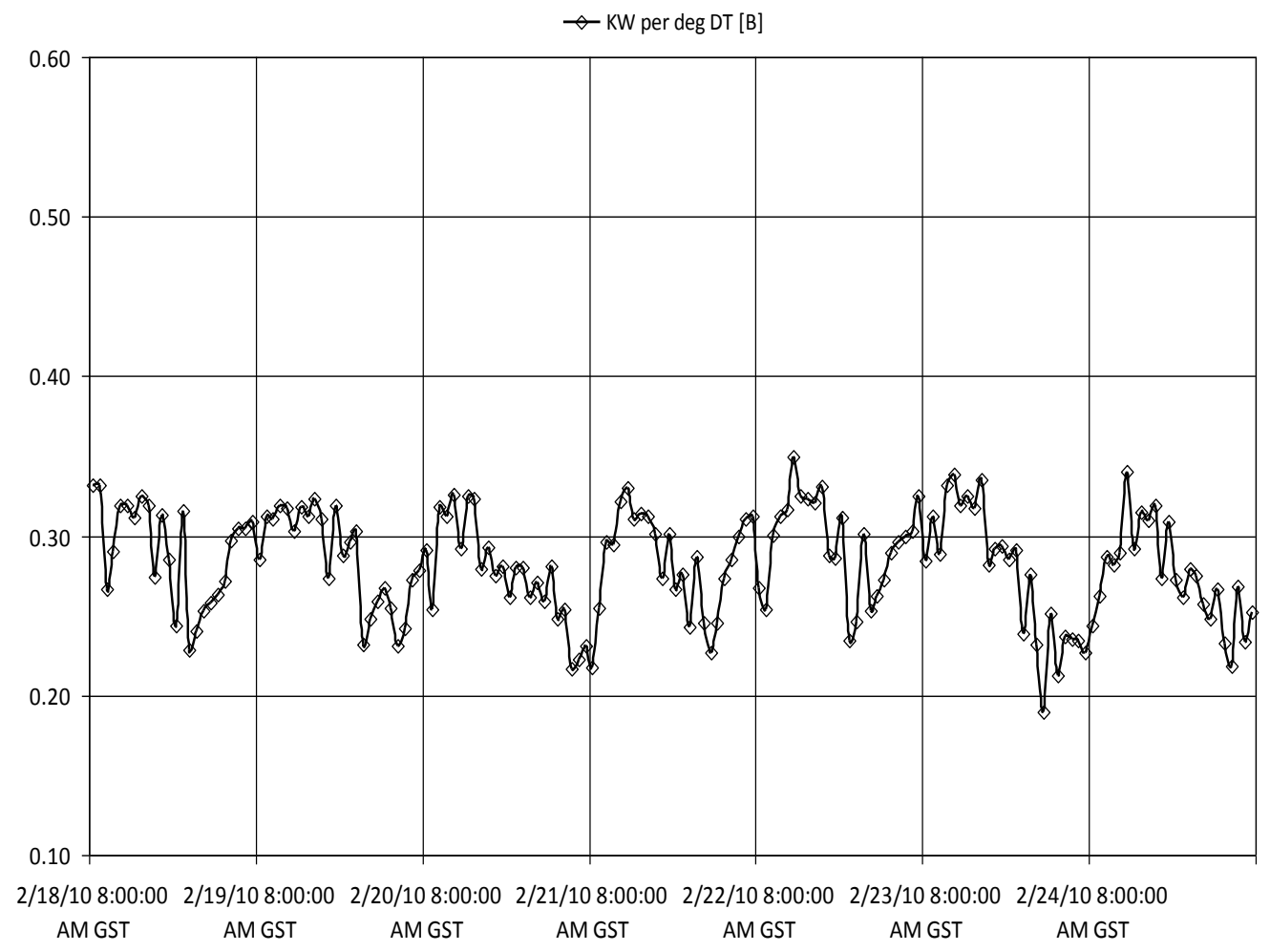

Figure 15. The weather corrected A/C energy demand for the dynamic case

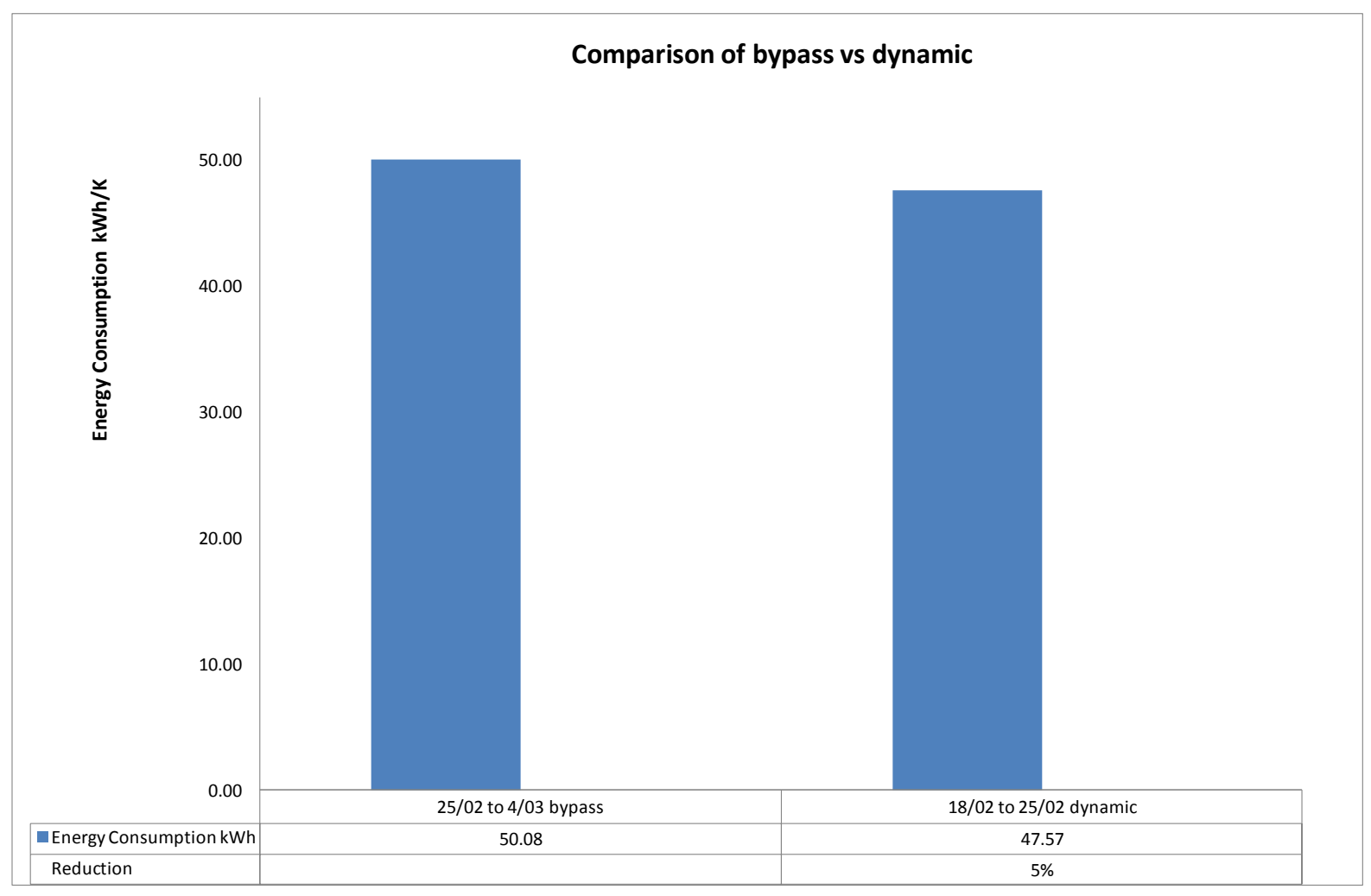

Figure 16. A to B comparison of the A/C normalised energy consumption 


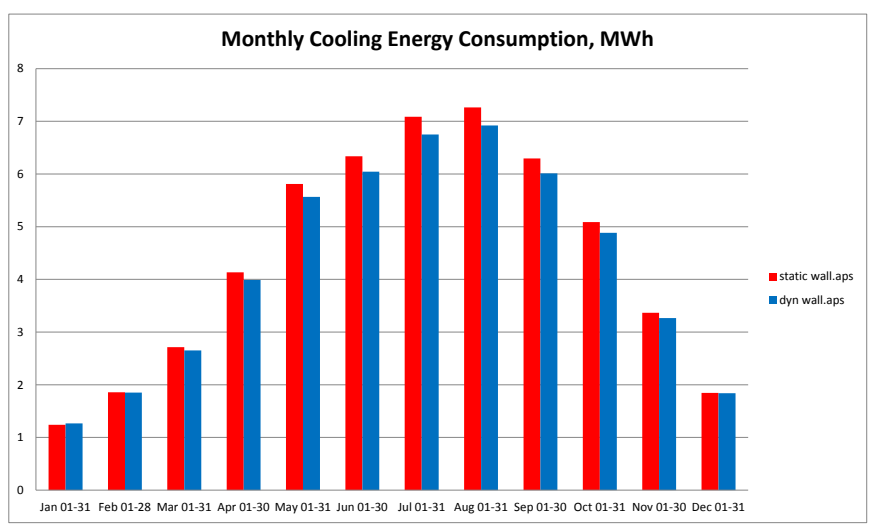

(a)

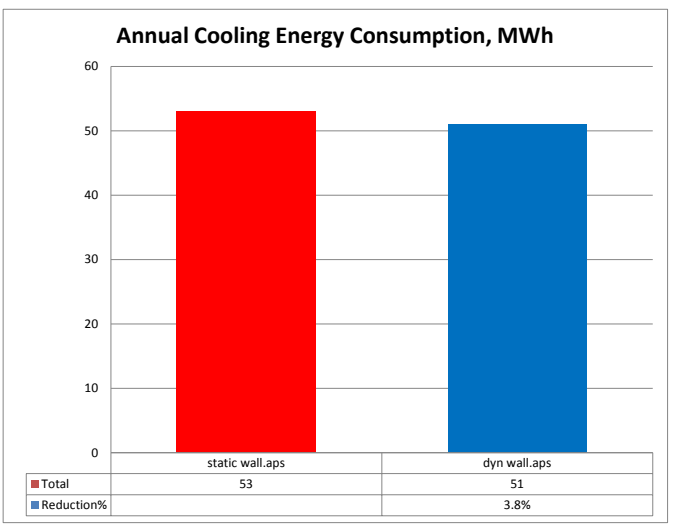

(b)

Figure 17. Cooling Energy Consumption a) Monthly; b) Annual

\section{CONCLUSIONS}

It is important to note that the dynamic insulation product used in the project was originally designed for the temperate climates of Northern Europe. In such climates, high solar gain, humidity and latent heat removal are different to those of the hot and humid Gulf Region.

The use of dynamic insulation in the façade leads to the creation of a dynamic building system that yields substantial indirect gains in the way that the air conditioning system operates. The theoretical $U$ value of the wall, at zero flow rate, was found to be $0.24 \mathrm{~W} / \mathrm{m}^{2} \mathrm{~K}$ and reduced dramatically to $0.05 \mathrm{~W} / \mathrm{m}^{2} \mathrm{~K}$ when the ventilation air flow varied from 0 to 1litres $/ \mathrm{s} / \mathrm{m}^{2}$. The theoretical dynamic $\mathrm{U}$ value at design ventilation rate of $0.8 \mathrm{litres} / \mathrm{s}$ is $0.063 \mathrm{~W} / \mathrm{m}^{2} \mathrm{~K}$ compared to a measured $\mathrm{U}$ value of $0.125 \mathrm{~W} / \mathrm{m}^{2} \mathrm{~K}$. The reduction in the fabric conduction gain was found to be $41 \%$ whereas the DSM showed $38 \%$. The results showed that the villa consumed 5.0\% less electrical energy for air conditioning. The DSM predicted that the annual cooling energy consumption from will be reduced by $3.8 \%$. Extra attention is clearly required to address latent heat gain and loss issues in the hot-humid climate of the UAE.

The use of dynamic insulation offers exceptionally low U-value thermal insulation but its effect does not end there. Isolating solar gain and related effects at the product and system levels is necessary and will go a long way to improving the overall performance of buildings in hot, sunny climates. In addition, the extract air from the conditioned space (e.g. toilets, kitchens, etc.) has a temperature normally between 27 and $30^{\circ} \mathrm{C}$ which means it could be used as a cooling source for the package air cooled condenser unit to improve the performance.

The Eco-Villa project has established the validity of using dynamic insulation in hot-humid climates. It has provided valuable insights into the strengths and weaknesses of the approach to dynamic insulation that was used. This has led to the development of a new class of dynamic insulation product optimised for the hot-humid climate of the Gulf Region. The product needs to be tested and its performance validated in further trials, involving different building types, in aid of roll out and wider use. 


\section{REFERENCES}

Anon., "Dynamic Insulation: the Next Step?" Australian Refrigeration, Air Conditioning and Heating, November, pp.47, 1984.

Arquis E. and Langlais C., "What Scope for 'Dynamic Insulation?" Batiment International Building Research and Practice, vol. 19, pp. 84-93, 1986.

Bailly N.R., "Dynamic Insulation Systems and Energy Conservation in Buildings" ASHRAE Transactions, vol. 93, part 1, pp. 447-468, 1987.

Claridge D.E., “The Measured Energy Impact of Air Leakage on Frame Wall Systems” Final Report, DOE, US, 1991.

Dalehaug A, Dynamic insulation in walls. Research report No 53, ISSN 0915-9215, Hokkaido prefectural cold region housing and urban research institute, Japan, 1993.

Dimoudi A, A. Androutsopoulos, S. Lykoudis, Experimental work on a linked dynamic and ventilated wall component, Energy and Buildings 36, p443-453, 2004.

Elsarrag E., M. Aboulnaga, A. Peacock and M. S. Imbabi, Dynamic insulation for energy conservation and improved indoor air quality in hot humid climates, Invited keynote paper, ASHRAE 5th Chapter Regional Conference (CRC), 01 - 03 November, Dubai, UAE, 2006.

Elsarrag E. and Imbabi M. Evaluation of dynamic insulation for zone ventilation and air conditioning in the gulf region, ASHRAE Symposium on Sustainability and Green Buildings; Kuwait, October 5, 2009.

Imbabi M S, Modular breathing panels for energy efficient, healthy building construction, Renewable Energy, Vol. 31, Issue 5, p 729-738, 2006.

Price L, S de la Rue de Can, J Sinton, E Worrell, Z Nan, J Sathaye and M Levine, Sectoral trends in global energy use and greenhouse gas emissions, Lawrence Berkley Laboratory, LBNL-56144, 2006.

Taylor, B J and M S Imbabi, Environmental design using dynamic insulation, ASHRAE Transactions, 106(1), p15-28, 2000

Taylor, B J, D A Cawthorne and M S Imbabi, Analytical investigation of the steady-state behavior of dynamic and diffusive building envelopes, Building and Environment, Vol.31(6), p519-525, 1996.

Taylor B J, and M S Imbabi, The effect of air film thermal resistance on the behaviour of dynamic insulation, Building \&Environment, Vol. 32(5), p397-404, 1997.

Taylor B J and M S Imbabi, Environmental design using dynamic insulation, ASHRAE Transactions, Vol. 106(1), p15-28, 2000. 